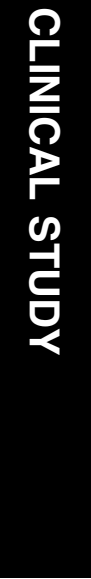

\title{
Accuracy of corneal flap thickness achieved by two different age MK-2000 microkeratomes
}

${ }^{1}$ Department of Ophthalmology, Buddhist Tzu Chi General Hospital and Institute of Medicine and Medicine Science, College of Medicine, Tzu Chi University, Hualien, Taiwan

${ }^{2}$ Department of Ophthalmology, Changhau Christian Hospital, Changhau, Taiwan

${ }^{3}$ Department of Physics, University of Maryland, College Park, MD, USA

Correspondence: C-P Lin, Attending physician, Department of Ophthalmology, Changhau Christian Hospital, 135 Nanhsiao Street, Changhau 500, Taiwan

Tel: + 886 912056223;

Fax: + 88638577161 .

E-mail: wps59@

yahoo.com.tw

${ }^{4}$ These authors have contributed equally to this work.

Received: 21 August 2008 Accepted in revised form: 10 December 2008

Published online:

13 February 2009

Conflict of interest: The authors declare no conflict of interest.

Financial interest: None

\section{Abstract}

Aims To investigate the accuracy of corneal flap thickness (FT) using two different age MK-2000 microkeratomes.

Methods The prospective cohort study enroled 260 patients with refractive error. Flaps were created using two microkeratomes $A$ and $B$ (new and aged, respectively) with 130$\mu \mathrm{m}$ heads in two patient groups and two times the same blade in both treated eyes of each patient. The variations in FTs were compared between two groups and between both operated eyes of each patient. The correlations were analysed between FT and CCT or keratometric power.

Results In the A and B groups, the average FTs were $123.3 \pm 18.7$ and $147.5 \pm 19.1 \mu \mathrm{m}$ respectively. Difference in measurements between the actual FTs of first eye operations in the A group and intended $130 \mu \mathrm{m}$ of FTs was not significant $(P=0.462)$, but those of second operated eyes in the A group and both treated eyes in the $B$ group were significant $(P<0.001)$. Second cut achieved a thinner flap and increased the variability in FT, and an aged microkeratome achieved a thicker flap than a new microkeratome and than that claimed by the manufacturer. Positive correlations were observed between preoperative CCT and FT $(P<0.05)$.

Conclusions The first eye operation by a new MK-2000 microkeratome achieves the accuracy of the intended FT. FTs varied between first and second cuts of each patient and between two different age MK-2000 microkeratomes. LASIK surgeons should compare FT when using an aged MK-2000 microkeratome, and frequent and periodic comparison of FT achieved by all microkeratomes may be also recommended.

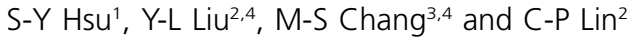

Eye (2009) 23, 2200-2205; doi:10.1038/eye.2008.435;

published online 13 February 2009

Keywords: cornea; flap thickness; microkeratome

\section{Introduction}

Excimer laser refractive surgery, laser in situ keratomileusis (LASIK), is a commonly used surgical technique for correcting refractive error. Before corneal stromal ablation by excimer laser during LASIK, a corneal flap is created using a microkeratome. Previous report indicates that unexpectedly thick flaps, leading to thin beds, might cause keratoectasia after LASIK and leave a thin residual stromal thickness (RST), even when using the identical metal microkeratome. ${ }^{1}$ Although the corneal flap can be created by the recently developed IntraLase femtosecond laser (IntraLase FS laser; IntraLase Crop.), flap thickness (FT) variations still exist. ${ }^{2}$ The target RST after surgery is often calculated by subtracting preoperative central corneal thickness (CCT) from FT (labelled on the microkeratome head) as well as ablation depth (automatically calculated by laser machine software). All surgeons use a minimum target RST to assess suitability for LASIK. Although $250 \mu \mathrm{m}$ remains the widely accepted minimum target RST for suitability for LASIK, the actual RST may be thinner than $200 \mu \mathrm{m}$ despite given a target RST of $250 \mu \mathrm{m}$ during LASIK. $^{3}$

Consequently, one of the factors which contributes to the difficulty involved in determining an RST value is the disparity in accuracy and reproducibility of microkeratome FT. ${ }^{4}$ Most surgeons do not routinely measure actual corneal FT during LASIK, and treatment 
decisions are often based merely on the FT prescribed by the microkeratome manufacturer. A previous study found that blades used on the second operated eyes yield thinner flaps. ${ }^{5}$ Additionally, most microkeratomes deviate measurably in the actual FTs achieved. ${ }^{6}$ Is there clear evidence that the corneal FTs do not deviate using the same model of two different age microkeratomes? To evaluate the variation of the corneal FTs using two different age MK-2000 microkeratomes in this study, the variations in FTs were compared between two different identification numbers of MK-2000 microkeratomes in two patient groups and between first and second operated eyes of each patient. Furthermore, the correlations were analysed between FT and CCT and between FT and keratometric power (K).

\section{Materials and methods}

This prospective cohort study analysed the outcome of LASIK surgery in 260 patients (172 women, 88 men; 520 eyes) with myopia or myopic astigmatism. Patients were excluded from surgery if they were younger than 20 years or had any history of uveitis, glaucoma, ocular trauma, severe dry eye syndrome, collagen disease, systemic disease, or drug allergy. The Institutional Review Board Ethics Committee approved the study and the participants gave their informed consent. The participants were advised that the study complied with Declaration of Helsinki research ethics guidelines. Baseline ocular examination included the following: anterior segment and anterior vitreous by slit-lamp biomicroscopy; posterior vitreous, disc, and macula by slit-lamp biomicroscopy with 90-D lens; peripheral retina by indirect ophthalmoscopy; intraocular pressure by non-contact tonometry (CT-80; Topcon, Tokyo, Japan); central corneal thickness (CCT) by ultrasonic pachymetry (MICROPACH 200P ${ }^{+}$; Sonomed, Lake Success, NY, USA); and K by AutoKeratoRefractometer (KR-8100; Topcon, Tokyo, Japan) and topography (CT 200; Dicon, San Diego, CA, USA). The corneal flaps were created using two different identification numbers of MK-2000 microkeratomes (Nidek, Gamagori, Japan), and each with $9-\mathrm{mm}$ suction rings and $130-\mu \mathrm{m}$ heads, respectively. The suction pressure setting was $65 \mathrm{~mm} \mathrm{Hg}$. The blade advance rate was $2 \mathrm{~mm} / \mathrm{s}$ of fixed speed. The blade oscillation rate was 9000 r.p.m. of fixed frequency. With the new microkeratome (microkeratome A), 120 patients were treated consecutively, and 140 patients were treated consecutively with the microkeratome which had been regularly used for approximately two thousands times and was 1-year-old (microkeratome B). All procedures were performed by a single surgeon.

The preoperative CCT was measured five times at the centre of the cornea by ultrasonic pachymetry, and average measurements were recorded. In each patient, the first and second eye operations were performed using a microkeratome with the same blade. In each group, half of the patient operations received first flap cuts on the right eyes, and the other half received first flap cuts on the left eyes. After cutting and lifting each flap, stromal bed thickness was again measured five times at the centre of the corneal stromal bed before laser ablation by ultrasonic pachymetry, and average measurements were recorded. Corneal FT was calculated by subtracting the central corneal stromal thickness from the preoperative CCT. The analysis of variability was performed using a coefficient of variation $(\mathrm{CV})$ defined as $100 \% \times \mathrm{SD} /$ mean. A temperature of $20-22^{\circ} \mathrm{C}$ was maintained throughout the procedure; humidity was maintained at $45-55 \%$ to ensure a stable operating condition during LASIK according to the manufacturer's prescription.

Statistical analyses were performed using SPSS software (SPSS 15.0; SPSS Institute Inc., Chicago, IL, USA). Mann-Whitney $U$-test was used to analyse the CCTs and Ks between both eyes of each patient and the thickness measurements between the actual FT of microkeratome and the intended FT $(130 \mu \mathrm{m})$ by $130-\mu \mathrm{m}$ head of microkeratome prescribed by the manufacturer and compare the FTs between two different identification numbers of MK-2000 microkeratomes in two patient groups and between both treated eyes of each patient. Pearson correlation method and linear regression analysis were used to verify correlations between FT and CCT and between FT and keratometric power (K). Statistical significance was defined as $P<0.05$.

\section{Results}

This study analysed 172 women and 88 men with a mean age of $28.8 \pm 5.1$ years. Average ages in microkeratome A and B groups were $29.3 \pm 5.3$ and $28.5 \pm 5.0$ years, respectively $(P=0.227)$. In each patient, the treated eye was analysed in further detail. The total average CCT was $545.8 \pm 30.7 \mu \mathrm{m}$. In the A group, the average CCT was $541.8 \pm 31.3 \mu \mathrm{m}$, with average $540.3 \pm 32.0 \mu \mathrm{m}$ (range, $475-619 \mu \mathrm{m})$ in the first operated eyes and $542.4 \pm 30.5 \mu \mathrm{m}$ (range, 478-625 $\mu \mathrm{m}$ ) in the second operated eyes (Table 1). Table 1 lists average CCTs and average Ks in the $\mathrm{A}$ and $\mathrm{B}$ groups. CCT or K did not significantly differ between the first and second operated eyes in either the A (CCT $P=0.891 ; \mathrm{K} P=0.779$ ) or B group (CCT $P=0.673$; $\mathrm{K} P=0.726)$.

In the A group, the average FT was $123.3 \pm 18.7 \mu \mathrm{m}$; with average $134.1 \pm 16.4 \mu \mathrm{m}$ (range, $102-180 \mu \mathrm{m}$ ) in the first operated eyes and 112.2 $\pm 14.5 \mu \mathrm{m}$ (range, $83-155 \mu \mathrm{m}$ ) in the second operated eyes $(P<0.001)$. In the $\mathrm{B}$ group, the averaged FT was $147.5 \pm 19.1 \mu \mathrm{m}$; with average 
Table 1 Central corneal thickness, keratometric power, and flap thickness measurements

\begin{tabular}{lccc}
\hline Average $\pm S D$ (range) & $C C T(\mu m)$ & $K(D)$ & $F T(\mu m)$ \\
\hline Total eyes & & & $123.3 \pm 18.7(83-180)$ \\
$\quad$ A & $541.8 \pm 31.3(475-625)$ & $43.67 \pm 1.39(39.50-47.75)$ & $147.5 \pm 19.1(104-182)$ \\
$\quad$ B & $549.1 \pm 29.9(474-625)$ & $43.72 \pm 1.14(40.75-45.75)$ & \\
First eyes & & & \\
A & $540.3 \pm 32.0(475-619)$ & $43.67 \pm 1.44(39.50-47.75)$ & $134.1 \pm 16.4(102-180)$ \\
B & $548.5 \pm 29.6(481-618)$ & $43.74 \pm 1.13(40.75-45.75)$ & $157.3 \pm 15.3(129-182)$ \\
Second eyes & & & \\
A & $542.4 \pm 30.5(478-625)$ & $43.67 \pm 1.35(39.50-47.50)$ & $112.2 \pm 14.5(83-155)$ \\
B & $549.6 \pm 30.3(474-625)$ & $43.71 \pm 1.16(40.50-45.75)$ & $137.7 \pm 17.5(104-172)$ \\
\hline
\end{tabular}

Abbreviations: CCT, central corneal thickness; K, keratometric power; FT, flap thickness; A, microkeratome A group; B, microkeratome B group; First eyes, first operated eyes; Second eyes, second operated eyes.

Table 2 Comparisons of the flap thickness between the actual measurement and intended thickness and between two different age MK-2000 microkeratomes

\begin{tabular}{|c|c|c|c|c|c|}
\hline P value & $130 \mu \mathrm{m}$ intended & $A$, first & $A$, second & $B$, first & $B$, second \\
\hline $130 \mu \mathrm{m}$ intended & & 0.462 & $<0.001^{*}$ & $<0.001^{*}$ & $<0.001^{*}$ \\
\hline A, first & 0.462 & & $<0.001^{*}$ & $<0.001^{*}$ & \\
\hline A, second & $<0.001^{*}$ & $<0.001^{*}$ & & & $<0.001^{*}$ \\
\hline B, first & $<0.001^{*}$ & $<0.001^{*}$ & & & $<0.001^{*}$ \\
\hline $\mathrm{B}$, second & $<0.001^{*}$ & & $<0.001^{*}$ & $<0.001^{*}$ & \\
\hline
\end{tabular}

Abbreviations: A, microkeratome A group; B, microkeratome B group.

Mann-Whitney $U$-test, ${ }^{*} P<0.05$.

$157.3 \pm 15.3 \mu \mathrm{m}$ (range, $182-129 \mu \mathrm{m}$ ) in the first operated eyes and $137.7 \pm 17.5 \mu \mathrm{m}$ (range, $172-104 \mu \mathrm{m}$ ) in the second operated eyes $(P<0.001$; Table 1$)$. The CVs of FTs in the first and second operated eyes were 12.2 and $12.9 \%$, respectively, in the A group and 9.7 and $12.7 \%$, respectively, in the $B$ group. In both $A$ and $B$ groups, the first eye operations produced a smaller $\mathrm{CV}$ than the second, indicating better precision.

Difference in thickness measurements between the FTs of first eye operations in the A group and the intended FT by $130 \mu \mathrm{m}$-head of microkeratome prescribed by the manufacturer was not significant $(P=0.462)$. Otherwise, differences in thickness measurements between the FTs of second eye operations in the A group and $130 \mu \mathrm{m}$ $(P<0.001)$, between the FTs of first eye operations in the $\mathrm{B}$ group and $130 \mu \mathrm{m}(P<0.001)$ and between the FTs of second eye operations in the B group and $130 \mu \mathrm{m}$ $(P<0.001)$ were statistically significant (Table 2$)$.

Differences in FT between first and second eye operations were significant in both the A $(P<0.001)$ and the $\mathrm{B}$ groups $(P<0.001)$. Differences in FT between the A and $\mathrm{B}$ groups were also significant in both first $(P<0.001)$ and second $(P<0.001)$ eye operations and in the average measurements of first and second eye operations $(P<0.001)$. The average FT in the B group (using the 1-year-old MK-2000 microkeratome) were significantly thicker than that in the A group (using the new MK-2000 microkeratome) in both the first $(P<0.001)$ as well as second $(P<0.001)$ eye operations (Table 2$)$. Positive correlations were observed between preoperative CCT and FT (A, first operated eyes, $P=0.011 ; A$, second operated eyes, $P=0.021 ; \mathrm{B}$, first operated eyes, $P<0.001$; $B$, second operated eyes, $P<0.001$; Figure 1 ), but none of the four groups revealed a significant correlation between $\mathrm{K}$ and FT $(P>0.05)$.

\section{Conclusion}

The precise corneal FT after cutting the flap is important for accurately correcting refraction by LASIK. ${ }^{7}$ During LASIK, the corneal FT is cut with a microkeratome before corneal stromal laser ablation. According to the results of previous studies controlled for patient age, time to follow-up or surgery, sphere and cylinder, laser settings, laser manufacturer, patient gender, and corneal thickness, increased corneal FT is a predictor of refractive undercorrection. ${ }^{7}$ A mechanical microkeratome is designed to cut a predetermined corneal FT based on the head gap specified by the manufacturer. ${ }^{8}$ Further, the femtosecond IntraLase laser reportedly produces variation in $\mathrm{FT}^{2}$ as well as increased incidence of post-LASIK inflammatory and fibrotic reaction. ${ }^{9}$ 

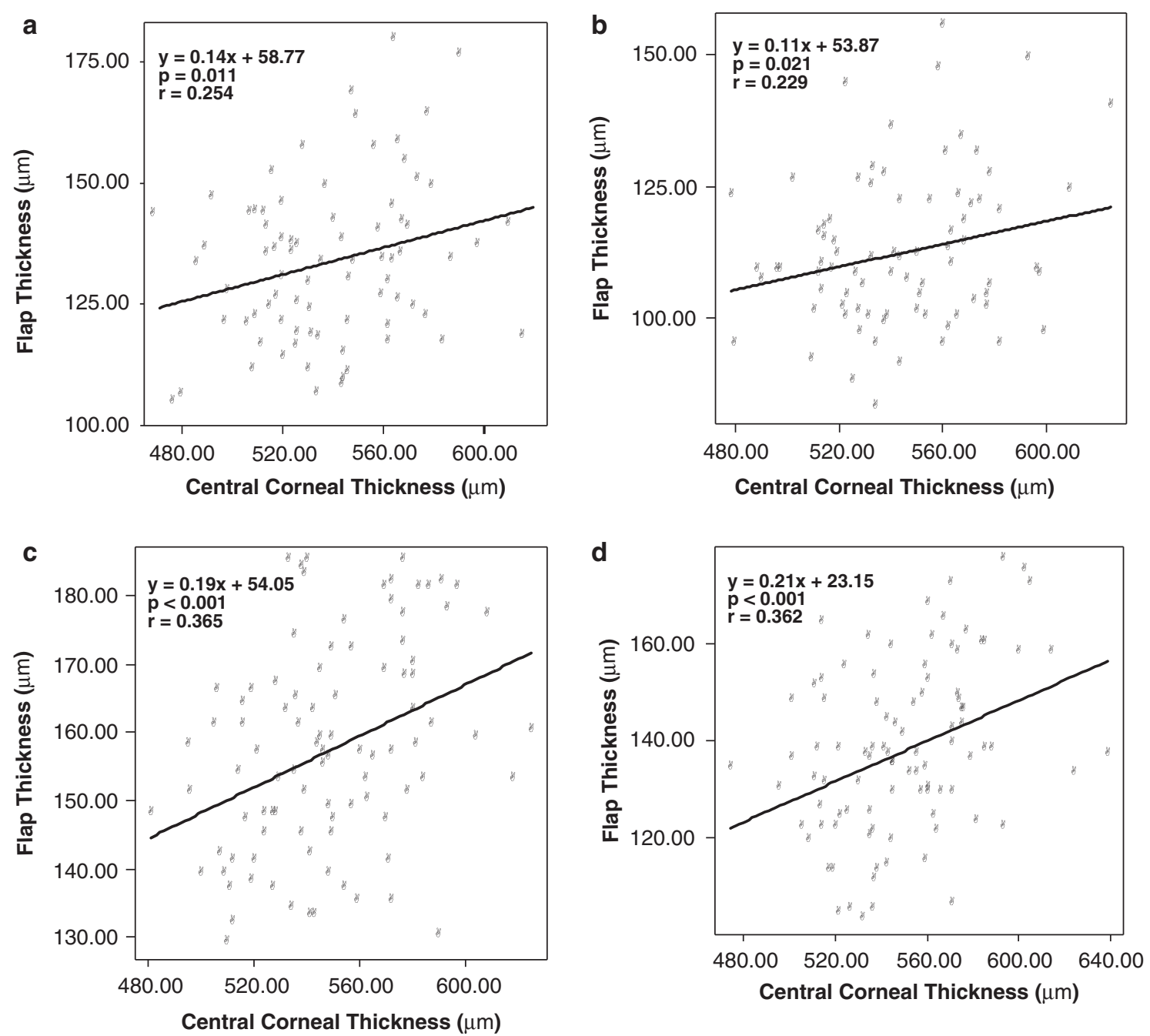

Figure 1 Positive correlations between central corneal thickness and flap thickness in the first operated eyes using the microkeratome A (a), in the second operated eyes using the microkeratome A (b), in the first operated eyes using the microkeratome B (c), or in the second operated eyes using the microkeratome B (d).

However, achieving precise FT using a microkeratome by a mechanical or intralaser technique is still a challenge in LASIK.

An ideal mechanical microkeratome should consistently produce the desired corneal FT. Theoretically, the distance between the fixed microkeratome plate and the edge of the metal blade determines FT during the flap cut. ${ }^{10}$ However, FT is still determined by variables such as microkeratome model, translation and oscillation rate, blade consistency across the cornea, suction pressure setting, cut mechanism, and preoperative CCT. ${ }^{5,10-14}$ Other than CCT and $\mathrm{K}$, the above variables were controlled in this study to reduce the number of confounding factors.

A review of study using a similar microkeratome reveals similar findings of a thinner FT achieved in the second cut. ${ }^{8}$ Additionally, previous reports comparing the discrepancy in FTs between first and second operated eyes using the same blade but different microkeratomes reveal similar thicker FT after the first operation than after the second. ${ }^{12,13,15}$ These reports correlate well with the findings of this study. Other authors speculate that the cause of the thinner flap achieved in the second cut is the increased dullness of the blade following the first cut. ${ }^{5,10}$ Some authors have postulated that salt crystals produced by the dried balanced salt solution after the first cut may produce a thinner second cut. ${ }^{13}$ In this study, however, oscillation of the blade in distiled water to remove salt particles did not appear to alter this phenomenon.

Some LASIK surgeons may measure actual corneal FT in the early stage and short term of using a new microkeratome. In this study with MK-2000 microkeratome, the A group results are consistent with 
previous reports ${ }^{8,16-18}$ that average FT achieved by a new MK-2000 microkeratome is thinner than that specified by the manufacturer. In contrast, average FT achieved by a 1-year-old MK-2000 microkeratome in B group was $147.5 \pm 19.1 \mu \mathrm{m} ; 157.3 \pm 15.3 \mu \mathrm{m}$ for the first cut and $137.7 \pm 17.5 \mu \mathrm{m}$ for the second cut. These comparative results show that average FT in B group is actually thicker than that in A group and than that claimed by the manufacturer. Schumer et $a l^{19}$ reported that two MK-2000 microkeratomes with $130-\mu \mathrm{m}$ heads (serial numbers 121 and 65) achieved average FTs of $129 \pm 21.8 \mu \mathrm{m}$ and $152 \pm 25 \mu \mathrm{m}$. However, the authors offered no explanation of the discrepant FT achieved by the two microkeratomes. As for MK-2000 microkeratome, the user should turn the screw of suction ring to bring the angled surface of suction ring into tightness and intimate contact with the matching angled part of microkeratome handpiece (Figure 2). When losing the intimate contact in preparation of MK-2000, the corneal FT would increase during surgery. In this study, MK-2000 microkeratome B had been regularly used for approximately 2000 times and was 1-year-old, but microkeratome A was new. Although both microkeratomes were serviced as required by the manufacturer, the screw of microkeratome B suction ring was aging and not so sharp to tighten the suction ring-handpiece connection compactly. For this reason, microkeratome aging may be a reason that flaps are thinner by MK-2000.

The repeated use of microkeratome blades can increase the variability in corneal FT and degrade the consistency and reproducibility of the cut. ${ }^{8,12}$ The CV of FT in this study was lower in the first operated eyes than the second in both A and B groups. This finding demonstrates the superior precision and the lower variability achieved in the first operations. This study of MK-2000 and several studies ${ }^{12,20-22}$ of various microkeratomes have reported a similar positive correlation between CCT and FT. One explanation is that

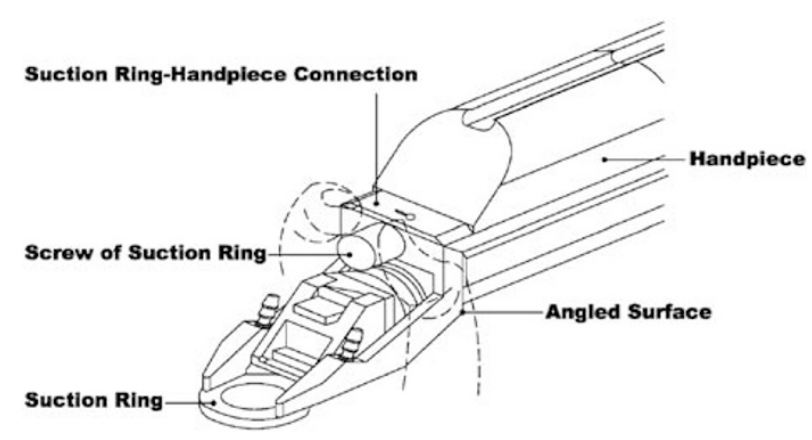

Figure 2 When using a MK-2000 microkeratome, the user should turn the screw of suction ring to bring the angled surface of suction ring into tightness and intimate contact with the matching angled part of microkeratome handpiece. the increased compressibility of a thicker cornea lead to a thicker FT during surgery. ${ }^{11}$ However, another study of the Moria LSK-One manual microkeratome revealed no such correlation. ${ }^{23}$ A possible explanation for the outcome in that report is the use of manual microkeratome without fixed translation speed as the blade crosses cornea. The association between $\mathrm{K}$ and FT is still unclear. ${ }^{13}$ In this study of both A and B groups, $\mathrm{K}$ did not correlate with FT in either first or second operated eyes.

Ultrasound pachymetry has commonly been performed by surgeons during surgery, and the FT can be calculated by subtracting RST from preoperative CCT. Previous reports indicate optical coherence tomography (OCT) can measure the flap using real-time image and gain the thickness measurement after LASIK. ${ }^{24,25}$ Although Avila et al had reported that OCT pachymetry agreed well with ultrasound pachymetry, ${ }^{26}$ however OCT flap measurement is not practiced universally. Further, Kim et $a l^{24}$ had reported that the boundaries after LASIK between the flap and stroma, especially in the central portion of the cornea, became ambiguous, and the flap measurement became difficult and increased variability after 1 month postoperatively. Other imaging method such as in vivo confocal microscopy has been used to measure FT, ${ }^{27}$ but its field of view is limited. The RST after LASIK is often calculated by subtracting preoperative CCT from FT as well as laser ablation depth, and measuring RST after laser ablation may be inaccurate due to overdehydration during LASIK. Wang et $a l^{28}$ had reported that the FT and postoperative CCT increased over time after surgery and this was caused by epithelial thickening. Randleman et $a l^{29}$ also demonstrated that the RST estimation after initial laser ablation based on an ultrasound subtracting method in initial LASIK is significantly lower and conservative than the RST estimation based on the calculation before enhancement procedure. For these reasons, estimating RST before laser ablation using ultrasound pachymetry to get actual corneal FT and precise postoperative RST in original surgery is vital for successful LASIK and desirable if laser enhancement necessary.

The findings of this study indicate that actual FT varies between different MK-2000 microkeratomes using $130-\mu \mathrm{m}$ metal heads. However, the first eye operation by a new MK-2000 microkeratome can achieve the accuracy of the intended FT, but the second eye operation or an aged MK-2000 microkeratome cannot. An aged MK-2000 microkeratome produces a thicker corneal FT. For this reason, LASIK surgeons should frequently compare FT, when using the same model of an aged MK-2000 microkeratome. Frequent and periodic comparison of cut thickness achieved by all microkeratomes may be also recommended. 


\section{References}

1 Genth U, Mrochen M, Walti R, Salaheldine MM, Seiler T. Optical low coherence reflectometry for noncontact measurements of flap thickness during laser in situ keratomileusis. Ophthalmology 2002; 109: 973-978.

2 Binder PS. One thousand consecutive intralase laser in situ keratomileusis flap. J Cataract Refract Surg 2006; 32: 962-969.

3 Reinstein DZ, Srivannaboon S, Archer TJ, Silverman RH, Sutton H, Coleman DJ. Probability model of the inaccuracy of residual stromal thickness prediction to reduce the risk of ectasia after LASIK part I: quantifying individual risk. J Refract Surg 2006; 22: 851-860.

4 Reinstein DZ, Srivannaboon S, Archer TJ, Silverman RH, Sutton H, Coleman DJ. Probability model of the inaccuracy of residual stromal thickness prediction to reduce the risk of ectasia after LASIK part II: quantifying population risk. J Refract Surg 2006; 22: 861-870.

5 Schultze RL. Microkeratome update. Int Ophthalmol Clin 2002; 42: 55-65.

6 Lin RT, Lu S, Wang LL, Kim ES, Bradley J. Safety of laser in situ keratomileusis performed under ultra-thin corneal flaps. J Refract Surg 2003; 19: S231-S236.

7 Flanagan GW, Binder PS. Role of flap thickness in laser in situ keratomileusis enhancement for refractive undercorrection. J Cataract Refract Surg 2006; 32: 1129-1141.

8 Arbelaez MC. Nidek MK 2000 microkeratome clinical evalution. J Refract Surg 2002; 18: S357-S360.

9 Munoz G, Albarran-Diego C, Sakla HE, Perez-santonja JJ, Alio JL. Femtosecond laser in situ keratomileusis after radial keratomy. J Cataract Refract Surg 2006; 32: 1270-1275.

10 Seiler T, Koufala K, Richter G. Iatrogenic keratoectasia after laser in situ keratomileusis. J Refract Surg 1998; 14: 312-317.

11 Seo KY, Wan XH, Jang JW, Lee JB, Kim MJ, Kim EK. Effect of microkeratome suction duration on corneal flap thickness and incision angle. J Refract Surg 2002; 18: 715-719.

12 Jackson DW, Wang L, Koch DD. Accuracy and precision of the Amadeus microkeratome in producing LASIK flaps. Cornea 2003; 22: 504-507.

13 Gailitis RP, Lagzdins M. Factors that affect corneal flap thickness with the Hansatome microkeratome. J Refract Surg 2002; 18: 439-443.

14 Giledi O, Mulhern MG, Espinosa M, Kerr A, Daya MS. Reproducibility of LASIK flap thickness using the Hanastome microkeratome. J Cataract Refract Surg 2004; 30: 1031-1037.

15 Shemesh G, Dotan G, Lipshitz I. Predictability of corneal flap thickness in laser in situ keratomileusis using three different microkeratomes. J Refract Surg 2002; 18: S347-S351.
16 Sarkisian KA, Petrov AA. Experience with the Nidek MK-2000 Microkeratome in 1220 Cases. J Refract Surg 2001; 17: 252-254.

17 Soloman KD, Donnenfeld E, Sandoval PH, Sarraf OA, Kasper TJ, Holzer MP et al. Flap thickness accuracy: comparison of 6 microkeratome models. J Cataract Refract Surg 2004; 30: 946-977.

18 Naripthaphan P, Vongthongsri A. Evaluation of the reliability of the Nidek MK-2000 microkeratome for laser in situ keratomileusis. J Refract Surg 2001; 17: S255-S258.

19 Schumer DJ, Bains HS. The Nidek MK-2000 microkeratome system. J Refract Surg 2001; 17(2 suppl): S250-S251.

20 Flanagan GW, Binder PS. Precision of flap measurements for laser in situ keratomileusis in 4428 Eyes. J Refract Surg 2003; 19: 113-123.

21 Choi YI, Park SJ, Song BJ. Corneal flap dimensions in laser in situ keratomileusis using the Innovatome automatic microkeratome. Korean J Ophthalmol 2000; 14: 7-11.

22 Thompson RW, Choi DM, Price MO, Potrezbowski L, Price Jr FW. Noncontact optical coherence tomography for measurement of corneal flap and residual stromal bed thickness after laser in situ keratomileusis. J Refract Surg 2003; 19: 507-515.

23 Jacobs BJ, Deutsch TA, Rubenstein JB. Reproducibility of corneal flap thickness in LASIK. Ophthalmic Surg Laser 1999; 30: 350-353.

$24 \mathrm{Kim} \mathrm{JH}$, Lee D, Rhee KI. Flap thickness reproducibility in laser in situ keratomileusis with a femtosecond laser: optical coherence tomography measurement. J Cataract Refract Surg 2008; 34(1): 132-136.

25 Li Y, Netto MV, Shekhar R, Krueger RR, Huang D. A longitudinal study of LASIK flap and stromal thickness with high-speed optical coherence tomography. Ophthalmology 2007; 114(6): 1124-1132.

26 Avila M, Li Y, Song JC, Huang D. High-speed optical coherence tomography for management after laser in situ keratomileusis. J Cataract Refract Surg 2006; 32(11): 1836-1842.

27 Gokmen F, Jester JV, Petroll WM, McCulley JP, Cavanagh HD. In vivo confocal microscopy through-focusing to measure corneal flap thickness after laser in situ keratomileusis. J Cataract Refract Surg 2002; 28(6): 962-970.

28 Wang J, Thomas J, Cox I, Rollins A. Noncontact measurements of central corneal epithelial and flap thickness after laser in situ keratomileusis. Invest Ophthalmol Vis Sci 2004; 45(6): 1812-1816.

29 Randleman JB, Hewitt SM, Lynn MJ, Stulting RD. A comparison of 2 methods for estimating residual stromal bed thickness before repeat LASIK. Ophthalmology 2005; 112(1): 98-103. 